\title{
Base Nacional Comum de Formação de Professores da Educação Básica: dilemas, embates e pontos de vista
}

\section{Common National Base for Basic Education Teacher Training: dilemmas, clashes and points of view} Base Nacional Común para la Formación del Profesorado de Educación Básica: dilemas, enfrentamientos y puntos de vista

\author{
Graça Reis ${ }^{1}$
}

Rafael Marques Gonçalves ${ }^{2}$

DOI: http://dx.doi.org/10.20435/serie-estudos.v0i0.1496

\begin{abstract}
Resumo: O presente texto tem como objetivo pensar a Base Nacional Comum de Formação (BNCFormação) em sua proposta inicial e, a partir dela, a BNCC já implantada em sua completude, desde 2019, organizando nosso debate em quatro momentos: no primeiro, assumimos a partir de Santos (2002) que estas duas políticas são o retrato de uma razão indolente que se apresenta nas quatro formas explicitadas pelo autor. Indicamos que essa indolência está presente nas políticas de currículo e formação estabelecidas por um modelo "eficientista", o qual retrata concepções de escola, aluno, professor e sociedade afastadas de um Estado Social de bem-estar que, entre outros aspectos, deveria ser constituído na diversidade e na diferença cultural. No segundo momento, tratamos sobre a BNCC compreendendo que é necessário conhecê-la para compreender melhor essa interdependência entre ela e a BNC-Formação e o ponto de vista que as unifica. No terceiro momento, trazemos uma discussão que perpassa as pesquisas com os cotidianos sobre os conceitos de raízes e opções (SANTOS, 2008) que demarcam nossos pontos de vista sobre currículo e formação docente. Por fim, destacamos que a formação de professores deveria estar pautada na ideia de que docentes são produtores de currículos, de seus materiais pedagógicos e dos processos de avaliação, e não meros transmissores do que vêm predeterminado pelas políticas educacionais que estão sendo desenhadas para formação docente.
\end{abstract}

Palavras-chave: Base Nacional; currículo; formação de professores; cotidiano escolar.

\footnotetext{
${ }^{1}$ Universidade Federal do Rio de Janeiro (UFRJ), Rio de Janeiro, Rio de Janeiro, Brasil.

2 Universidade Federal do Acre (Ufac), Rio Branco, Acre, Brasil.
} 


\begin{abstract}
This paper's goal is to reflect on the Common National Base for Basic (BNC-Formação) in its initial proposal and, from it, analyze the BNCC. The BNCC is fully implemented since 2019; we organize our debate in four moments: first, we assume from Santos (2002) that both policies are reproductions of an indolent reason, which is presented in the four ways theorized by the author. We indicate that the indolent reason is present among the curriculum and training policies established by an "efficientist" model. The "efficientist" model is based on a school, student, teacher, and society concepts aloof from the Welfare State. The State, among other aspects, should be shaped by diversity and cultural differences. Secondly, we conduct a study of the BNCC, thus understanding that it is necessary to deepen our research to understand the interdependence between BNCC and BNC-Formação and the point of view that unifies them. Third, we bring a discussion that permeates the research with ordinary concepts of roots and options (SANTOS, 2008), which impacts our points of view about curriculum and teacher training. Finally, we conclude that teacher trainings should incorporate the idea of teachers as producers of curricula, pedagogical materials, and evaluation processes and not message senders of predetermined contents designed in the educational policies.
\end{abstract}

Keywords: teacher training policy; curriculum policy; undergraduate curriculum.

Resumen: El presente texto pretende pensar sobre la Base Nacional Común para la Formación (BNC-Formação) en su propuesta inicial y, a partir de ella, la BNCC ya implementada en su totalidad, desde 2019, organizando nuestro debate en cuatro momentos: en el primero, asumimos de Santos (2002) que estas dos políticas son el retrato de una razón indolente que aparece en las cuatro formas explicadas por el autor. Señalamos que esta indolencia está presente en las políticas curriculares y de formación establecidas por un modelo "eficientista", lo cual retrata concepciones de escuela, alumno, docente y sociedad alejadas de un Estado de bienestar social que, entre otros aspectos, debe constituirse en el diversidad y diferencia cultural. En el segundo momento, nos ocupamos de la BNCC entendiendo que es necesario conocerla para comprender mejor esta interdependencia entre ella y BNC-Formação y el punto de vista que las unifica. En el tercer momento, traemos una discusión que atraviesa la investigación de los cotidianos sobre los conceptos de raíces y opciones (SANTOS, 2008) que demarcan nuestros puntos de vista sobre currículo y formación docente. Finalmente, enfatizamos que la formación docente debe basarse en la idea de que los docentes son productores de currículos, sus materiales didácticos y procesos de evaluación, y no meramente transmisores de lo predeterminado por las políticas educativas que se están diseñando para la formación docente.

Palabras clave: Base Nacional; plan de estudios; formación de profesores; seguro escolar.

\title{
1 UM PONTO DE VISTA INICIAL
}

Do ponto de vista das estatísticas, se uma pessoa recebe mil dólares e outra não recebe nada, cada uma dessas duas pessoas aparece recebendo 500 dólares no cálculo da receita per capita. Do ponto de vista da luta contra a inflação, as medidas de ajuste são um bom remédio. Do ponto de vista de quem as padece, as medidas de ajuste multiplicam o cólera, o tifo, a tuberculose e outras maldições. Do ponto de vista do oriente do mundo, o dia do ocidente é noite. Na Índia, quem está de luto se veste de branco. (GALEANO, 1999, s. p.) 
Segundo Alves (2014), diante do que "se decidiu chamar a crise da escola", as convicções políticas costumam apresentar soluções fáceis para as "grandes discussões necessárias entre as tantas posições e imagens sobre as questões curriculares". Atualmente, no Brasil, "essas questões se apresentam como a necessidade de uma Base Nacional Comum" (BNC) (ALVES, 2014, p. 1467). Alves está se referindo, em seu texto, à Base Nacional Comum Curricular (BNCC) aprovada entre os anos de 2017 e 2018 para os diferentes segmentos da Educação Básica. No entanto, sua discussão cabe também para a produção da "necessidade" de uma Base Nacional Comum para a Formação Inicial e continuada de Professores (BNC-Formação), que é proposta a partir da ideia de que a formação inicial de professores precisa estar pautada nos conteúdos que integram a BNCC.

Galeano, na epígrafe deste texto, alerta para o fato de que há diversos lugares de onde podemos perceber o mundo. Ou seja, nossos pontos de vista diferem porque o percebemos de espaços, tempos, culturas diferentes. No entanto, há pontos de vista que se assumem como únicos, foram tornados hegemônicos pelo apagamento de outros modos de pensar, ver e sentir.

Assim, percebemos a formulação das políticas de currículo e formação docente nesses e, também, em outros tempos. São pontos de vista que prevalecem como únicos possíveis.

Nosso objetivo neste texto é pensar especificamente a BNC-Formação em sua proposta inicial e, a partir dela, a BNCC já implantada em sua completude, desde 2019. Assumimos, para isso, junto de Santos (2002), que estas duas políticas - as quais, em nosso entendimento, são apenas UM ponto de vista, embora apresentado como ÚNICO possível -, são o retrato de uma razão indolente que se apresenta nas quatro formas explicitadas pelo autor: ela é impotente, ou seja, "não se exerce porque pensa que nada pode fazer contra uma necessidade concebida como exterior a ela própria" (p. 239); ela é arrogante, porque "não sente necessidade de exercer-se porque se imagina incondicionalmente livre e, por conseguinte, livre da necessidade de demonstrar a sua própria liberdade" ( $p$. 240); é metonímica, reivindicando-se "como única forma de racionalidade e, por conseguinte, não se aplica a descobrir outros tipos de racionalidade" (p. 240); e é proléptica, pois "não se aplica a pensar o futuro, porque julga que sabe tudo a respeito dele e o concebe como uma superação linear, automática e infinita do presente" (p. 240). 
Dessa forma, nós nos propomos a problematizar esse ponto de vista, indicando que essa indolência está presente nas políticas de currículo e formação estabelecidas por um modelo "eficientista", o qual retrata concepções de escola, aluno, professor e sociedade afastadas de um Estado Social de bem-estar que, entre outros aspectos, deveria ser constituído pelos diferentes pontos de vista e pela convivência na diversidade e na diferença cultural. Com isso, ressaltamos que há um debate, como já explicitado por Alves (2014), que foi deixado de lado pelas políticas que têm apresentado soluções fáceis para o que deveriam ser grandes discussões.

Assim, fica estabelecida a nossa pergunta: para que e para quem queremos formar os docentes brasileiros?

A resposta dada pelas políticas de formação e de currículo, neste momento, indica-nos que é um docente que sabe ensinar os conteúdos da BNCC e que deve "ser formado" por meio das competências estabelecidas em ambos os documentos, pois estes integram um sistema de políticas educacionais que são interdependentes, alinhados e padronizados. Segundo Rodrigues, Pereira e Mohr (2020, p. 9). "interdependência, alinhamento e padronização talvez nunca antes vistos e explicitamente declarados em seus textos". Assim:

[...] a BNCC integra a política nacional da Educação Básica e vai contribuir para o alinhamento de outras políticas e ações, em âmbito federal, estadual e municipal, referentes à formação de professores, à avaliação, à elaboração de conteúdos educacionais e aos critérios para a oferta de infraestrutura adequada para o pleno desenvolvimento da educação. (BRASIL, 2018a, p. 8).

Ainda:

O texto indica que os currículos dos cursos de formação dos docentes vão ter como referência a Base Nacional Comum Curricular (BNCC), documento que define os direitos de aprendizagem de todos os alunos das escolas brasileiras. As instituições de ensino com cursos de licenciatura terão no mínimo dois anos para fazer a adequação dos currículos à base ${ }^{3}$.

E mais:

A primeira tarefa de responsabilidade direta da União será a revisão da formação inicial e continuada dos professores para alinhá-las à BNCC. A

${ }^{3}$ Disponível em: http://portal.mec.gov.br/component/content/article/12-noticias/acoes-programas-e-projetos-637152388/85481-resolucao-define-diretrizes-para-formacao-de-professores?!temid=164. Acesso em: 28 jul. 2020. 
ação nacional será crucial nessa iniciativa [...]. Diante das evidências sobre a relevância dos professores e demais membros da equipe escolar para o sucesso dos alunos, essa é uma ação fundamental para a implementação eficaz da BNCC. (BRASIL, 2018a, p. 20).

A fim de desenvolver esta proposta de discussão, nosso texto está dividido em quatro seções que nos ajudarão a tecer a ideia de que, apesar de se desenharem como pontos de vista únicos, essas políticas são apenas uma forma de conceber a formação de professores e o currículo que busca retirar a complexidade das ideias que estão em disputa, a todo tempo, nos campos de estudo e pesquisa.

Começaremos o texto apresentando o ponto de vista que norteia a BNCFormação a partir da primeira versão do documento e das análises realizadas por Albino e Silva (2019) e Rodrigues, Pereira e Mohr (2020).

Em seguida, na segunda seção, traremos uma discussão sobre a BNCC, compreendendo que é necessário conhecê-la para compreender melhor essa interdependência entre ela e a BNC-Formação e o ponto de vista que as unifica. Na terceira seção, trazemos uma discussão que perpassa as pesquisas com os cotidianos sobre os conceitos de raízes e opções (SANTOS, 2008) que demarcam nossos pontos de vista sobre currículo e formação docente.

Por fim, em nossas considerações finais, apresentamos como se desenham no cotidiano docente os pontos de vista dessas políticas curriculares e de formação.

\section{O PRIMEIRO PONTO - DO PONTO DE VISTA DO NATIVO, PITORESCO É O TURISTA4: A BASE NACIONAL COMUM PARA A FORMAÇÃO INICIAL DE PROFESSORES DA EDUCAÇÃO BÁSICA}

Para compreender a retomada do projeto de formação por competência, de avaliação e de certificação dos docentes, em dezembro de 2018, é preciso referir-se ao Golpe jurídico-institucional, que levou ao impeachment da presidente Dilma Rousseff, em 31 de agosto de 2016. Entre os partidos que realizaram e apoiaram o golpe, o Partido da Social Democracia Brasileira (PSDB) teve grande participação. Como resultado, dessa atuação, o PSDB ocupou cargos importantes no Governo de Michel Temer, entre eles, no Ministério da Educação. Tal situação, conduziu novamente ao MEC profissionais que tinham atuado na definição das políticas de formação do Governo de FHC,

$\overline{{ }^{4} \text { Conf. Galeano, } 1999 .}$ 
como as professoras Guiomar Namo de Mello e Maria Helena Guimarães Castro. Nesse contexto, foram retomadas, com prioridade, propostas implantadas no governo do PSDB. (ALBINO, SILVA, 2019, p. 145).

A BNC-Formação foi instituída por meio da Resolução CNE/CP n. 2, de 20 de dezembro de 2019, que define as Diretrizes Curriculares Nacionais para a Formação Inicial de Professores para a Educação Básica e institui a Base Nacional Comum para a Formação Inicial de Professores da Educação Básica (BNC-Formação). A primeira proposta de uma BNC-Formação (BRASIL, 2018b) foi apresentada em dezembro de 2018, em uma primeira versão, bem ao final do governo Temer. É importante registrar que optamos pela análise do documento de 2018 porque a Resolução CNE/CP n. 2, de 20 de dezembro de 2019, em seu artigo 1ํㅡ, define que a BNC-Formação aparecerá no documento como forma de anexo. Ao analisá-lo, percebemos que o texto da proposta foi sucumbido, ou seja, encontramos somente um quadro-listagem de competências.

Art. 10 A presente Resolução define as Diretrizes Curriculares Nacionais para a Formação Inicial em Nível Superior de Professores para a Educação Básica e institui a Base Nacional Comum para a Formação Inicial de Professores da Educação Básica (BNC- Formação), constante do Anexo, a qual deve ser implementada em todas as modalidades dos cursos e programas destinados à formação docente.

$[\ldots]$

Parágrafo único. As competências gerais docentes, bem como as competências especificas e as habilidades correspondentes a elas, indicadas no Anexo que integra esta Resolução, compõem a BNC-Formação. (BRASIL, 2018b)

Nesse sentido, compreendemos a importância de analisar o documento da proposta de 2018, a fim de discutir os referenciais e as discussões teóricas que embasaram a construção dessas competências.

Esse documento é de difícil acesso. Fizemos diversas buscas pelo Google e, diferentemente do documento da BNCC, que não necessita de uma busca muito refinada para ser encontrado, não conseguimos chegar ao documento da primeira versão da BNC-Formação por essa via. Precisamos utilizar o link encontrado como nota de rodapé ${ }^{5}$ no texto de Rodrigues, Pereira e Mohr (2020, p. 8).

5 Disponível em: http://portal.mec.gov.br/index.php?option=com_docman\&view=down load\&alias=105091-bnc-formacao-de-professores-v0\&category_slug=dezembro-2018- 
Encontramos um documento com 65 páginas dividido em apresentação e quatro capítulos, além de uma lista bibliográfica com 45 referências citadas. No primeiro capítulo, encontramos o estado da arte da formação de professores com três tópicos: histórico da formação de professores no Brasil, referenciais docentes no Brasil e referenciais docentes internacionais. O capítulo 2, intitulado "Visão sistêmica da formação", apresenta um conjunto de seis ações e políticas interligadas à BNC-Formação: formação inicial; residência pedagógica; Enade licenciaturas; formação continuada; estágio probatório; plano de carreira e avaliação. O capítulo 3 traz a matriz de competências profissionais e está dividido em seis tópicos: competências profissionais; conhecimento profissional; prática profissional; engajamento profissional; sinergia entre as funções de formação; competências profissionais docentes. Por último, temos o capítulo 4, intitulado "Limites e indicações".

Sobre os autores do documento, encontramos em Rodrigues, Pereira e Mohr (2020) uma breve apresentação que já nos indica de que lugar o ponto de vista da BNC-Formação é construído.

São seis autores os autores do documento: Maria Alice Carraturi Pereira, Guiomar Namo de Mello, Bruna Henrique Caruso, Fernando Luiz Abrucio, Catarina Ianni Segatto, Lara Elen Ramos Simielli, sendo que a primeira consta como "Organizadora". Há também três colaboradores: Caroline Tavares da Silva, Francisco Aparecido Cordão, Bahij Amin Aur.

Em uma breve análise do currículo Lattes de cinco autores (de quatro não encontramos currículo naquela plataforma) percebe-se que eles têm formação acadêmica e experiência profissional que nos permite caracterizá-los como pessoas que são/estão ligadas a grupos de "reformadores empresariais" ${ }^{2} \mathrm{e}$

pdf\&Itemid=30192. Acesso em: 28 jul. 2020.

6 O termo "Corporate reformers" (traduzido como "reformadores empresariais da educação" no Brasil) é o termo cunhado por Diane Ravitch no livro "Vida e morte do grande sistema escolar americano", publicado em 2011. Ao utilizá-lo, a autora se refere a uma coalizão entre políticos, mídia, empresários, empresas educacionais, institutos e fundações privadas e pesquisadores alinhados com a ideia de que o mercado e o modo de organizar a iniciativa privada é uma proposta mais adequada para a melhoria da educação americana, o que contrasta com as propostas feitas pelos educadores profissionais, que apostam na transformação social, visando ao desenvolvimento da solidariedade entre as pessoas, à valorização da auto-organização dos estudantes e do trabalho coletivo, bem como ao respeito à diversidade cultural (RODRIGUES; PEREIRA; MOHR, 2020, p. 7). 
não a "educadores profissionais". (FREITAS, 2012 apud RODRIGUES; PEREIRA; MOHR, 2020, p. 7).

Percebemos, já numa primeira análise do documento ${ }^{7}$, algumas questões mais gerais, e é com elas que vamos trabalhar aqui, a fim de contextualizar a produção dessa política pública e seu ponto de vista único que retira do processo de formação de professores a complexidade, as discussões e tensões que precisam ser encaradas.

Já na página 5, na apresentação, encontramos o estado da arte da formação de professores, que diz que "a origem socieconômica do aluno, sobre a qual a escola não tem controle, embora seja um fator que pese na determinação do desempenho escolar, pode ser compensada pela ação da escola" (BRASIL, 2018b, p. 5).

Essa afirmativa nos permite inferir que há uma concepção retratada no documento que exime o Estado dos seus deveres perante a sociedade, principalmente quando pensamos o Brasil, um país com índices enormes de desigualdade social. Além disso, ao eximir o Estado, trazendo a escola como espaço e tempo compensatório de mazelas sociais, há uma intenção de culpabilizar os docentes, que passam a ser responsabilizados por qualquer baixo índice de aprendizagem escolar, mesmo quando a comunidade atendida não apresente as mínimas condições necessárias para um bem viver.

Esse discurso, para nós, é cortina de fumaça, pois a escola, de fato, não tem controle sobre a origem socieconômica do aluno; isso é obrigação do Estado (representado também pela escola), que deveria promover políticas que melhorem a qualidade de vida da população. No entanto, qualquer leitor desavisado pode tender a concordar que, de fato, a escola não tem controle sobre as questões socioeconômicas e que cabe ao professor, em qualquer situação, "ensinar" aquilo que deve ser ensinado a todo o seu alunado, apagando, assim, as subjetividades dos sujeitos e as dificuldades de não se ter alimentação e moradias adequadas, por exemplo. Assim, o Estado fica desobrigado de seu papel essencial na Educação. Nessa lógica em que o professor se torna o único responsável pelo que acontece nos processos de ensino e aprendizagem, é necessário que se criem políticas voltadas para "ensinar" ao professor como ser professor.

Mais adiante, na página 17, o documento apresenta uma pesquisa realizada pelo Centro de Estudos e Pesquisas em Educação, Cultura e Ação Comunitária

\footnotetext{
${ }^{7}$ Vamos trabalhar apenas discutindo aspectos da formação inicial presentes no documento.
} 
(Cenpec). Numa busca realizada no Google, encontramos o site ${ }^{8}$ que apresenta o Cenpec e, na aba "sobre", descobrimos que se trata de uma "organização da sociedade civil, sem fins lucrativos, que tem como objetivo o desenvolvimento de projetos, pesquisas e metodologias voltados à melhoria da qualidade da educação pública e a incidência no debate público".

A pesquisa realizada é apresentada como se segue:

Os entrevistados foram escolhidos de maneira não aleatória, por conta de sua participação no debate sobre políticas educacionais ou como formuladores de políticas educacionais e dividiram-se da seguinte forma: 17 pesquisadores, 14 gestores do terceiro setor, 10 gestores e ex-gestores públicos, 7 membros e ex-membros do CNE, seis gestores de IES privadas e um sindicalista. A pesquisa resultou em quatro visões distintas sobre referenciais no Brasil. O primeiro grupo, que se mostrou contrário ao tema, argumentou que "já existem Diretrizes" e, assim, há outras políticas prioritárias. Para eles, os referenciais servem à lógica de gestão por resultados. No segundo grupo aparecem os atores que se mostram favoráveis a referenciais menos estruturados, enfatizando a questão mais contextual do saber docente. Para esse grupo, os referenciais melhoram a formação dos professores e a qualidade da educação. O terceiro grupo, por sua vez, é favorável a referenciais mais estruturados, com ênfase na dimensão didática/pedagógica do saber docente. Para eles, é fundamental pensar na transposição didática, em como transpor o conhecimento em prática. Por fim, o quarto grupo englobou os atores favoráveis a referenciais mais estruturados com ênfase na dimensão técnica do saber docente. Este grupo, assim como o grupo anterior, citou a questão dos protocolos médicos e de treinamentos de esportistas, enfatizando a dimensão técnica com foco no aprendizado dos alunos. Os entrevistados citaram, ainda, a bonificação dos professores e o uso de referenciais para a avaliação docente e como ferramenta para o plano de carreira como pontos positivos. (BRASIL, 2018b, p. 17).

Esta é mais uma das características que percebemos no texto do documento: pouca relação com a pesquisa acadêmica e científica nacional. Ou seja, foi necessário usar uma organização da sociedade civil, sem fins lucrativos, para fazer um levantamento que poderia ter sido realizado a partir da pesquisa em trabalhos sobre o tema nos encontros da Associação Nacional pela Formação dos Profissionais da Educação (Anfope), da Associação Nacional de Pós-Graduação e

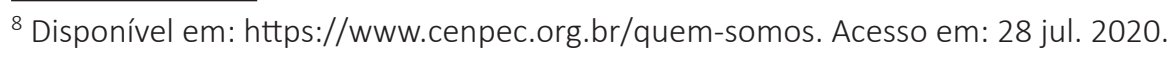


Pesquisa em Educação (ANPEd), entre outras associações científicas nacionais, assim como no Encontro Nacional de Didática e Práticas de Ensino (Endipe) ou em bases de dados de teses e dissertações da Capes. Não há um link ou orientação sobre como se chegar a esta pesquisa para conhecê-la. O que nos faz levantar algumas perguntas: por que esses sujeitos e não outros foram escolhidos para a pesquisa? Como se deu o cálculo que levou a esse número de pessoas pesquisadas de cada área? De que forma a pesquisa foi realizada? Que perguntas exatamente foram realizadas? Sabemos que não há neutralidade na pesquisa, o que significa que a escolha dos sujeitos, as perguntas a serem respondidas, a forma e o local podem influenciar as respostas a serem colhidas.

Outro dado interessante aparece na seção que está dedicada à apresentação e à discussão de referenciais docentes: os achados brasileiros ocupam duas páginas, enquanto os achados internacionais ocupam mais de seis páginas. Além disso, a fim de ratificar a pouca produção brasileira, o texto afirma em sua página 18 que "há poucas iniciativas ou estudos no Brasil de referenciais de formação". Somente para o Endipe 2020, tivemos 814 trabalhos sobre formação docente inscritos no Encontro. Com isso, queremos dizer que a informação contida na Base se caracteriza como uma inverdade que serve apenas para justificar a escoIha em priorizar os referenciais internacionais, lembrando que não são quaisquer referenciais internacionais, mas sim aqueles escolhidos de forma a respaldar esse único ponto de vista apresentado no documento.

Uma das referências que respalda esse ponto de vista é uma pesquisa realizada pela McKinsey \& Company de $2008^{9}$ (BRASIL, 2018b, p. 5-6), apresentada no site ${ }^{10}$ como "Conteúdo de grande relevância estratégica para o cenário brasileiro, diretamente aplicável ao mercado e elaborado pelos principais líderes da McKinsey \& Company no Brasil e no mundo", cujo resultado afirma que "a qualidade dos professores é a alavanca mais importante para melhorar os resultados dos alunos".

Assim, do ponto de vista do texto, há a ideia de que o baixo desempenho docente, medido pelos baixos resultados das escolas brasileiras nos exames nacionais e internacionais, mostram indícios de uma formação inicial e continuada precárias, trazendo a BNCC como uma "oportunidade ímpar para a implementação

\footnotetext{
9 A pesquisa examina o sistema educacional de 17 países - os dez com melhor desempenho nas provas do Pisa, mais sete países cujos resultados indicavam uma forte tendência à melhoria.

${ }^{10}$ Disponível em: https://www.mckinsey.com.br. Acesso em: 28 jul. 2020.
} 
de uma política de Estado que promova o aprimoramento da atuação dos professores em sala de aula com vistas a impactar positivamente o processo educativo dos brasileiros" (CONSED, 2017), o que reduz a formação docente à ideia de uma prática simétrica, linear e instrumental, difundida nas DCNs (2001 e 2002), que fomentaram um discurso formativo em que os professores deveriam aprender, de forma engessada e tecnicista, o conteúdo a ser ministrado em sala de aula.

Dessa forma, evidencia-se como política educacional a ideia de que não é necessário um compromisso do Estado na promoção de uma sociedade democrática, justa e inclusiva, mas sim um processo de formação de professores que os responsabilize pela formação de cidadãos que devem atuar e produzir uma sociedade democrática, justa e inclusiva.

A escolha das palavras também nos dá indícios das concepções que estão em jogo nas políticas educacionais. E, nesse caso, traduz "uma concepção de formação e um perfil de professor que [servem] de sustentação para o desenvolvimento de políticas de formação docente de caráter técnico-instrumental, orientadas por uma perspectiva compensatória de formação" (SANTOS 2016, p. 106).

Na página do Ministério da Educação, encontramos:

A capacitação dos docentes é o primeiro passo para a melhoria dos índices de educação no país. Pensando nisso, o Ministério da Educação (MEC) publicou resolução que institui a Base Nacional Comum para a Formação Inicial de Professores da Educação Básica (BNC-Formação) e define diretrizes para a política. ${ }^{11}$

"Capacitação" é o ato ou efeito de capacitar, ou seja, dar capacidade de alguma coisa a alguém; nesse caso, o professor precisa ser capacitado por alguém para realizar o seu trabalho, como alguém que não participa no processo como sujeito de conhecimentos, e sim como um ser "capacitável" para o desempenho de uma ação técnica.

Nesse sentido, é importante trazer para a discussão sobre esta Base Nacional Comum de Formação a ideia de competências na qual o texto é sustentado, pois, segundo Sácristan (2011, p. 7 apud ALBINO, SILVA, 2019, p. 141), as competências são umas dessas "linguagens e metáforas que nos levam a denominar de forma

${ }^{11}$ Disponível em: http://portal.mec.gov.br/component/content/article/12-noticias/acoes-programas-e-projetos-637152388/85481-resolucao-define-diretrizes-para-formacao-de-professores? Itemid=164. Acesso em: 28 jul. 2020. 
aparentemente nova aquilo que, até então, reconhecíamos de outra forma". O documento apresenta três dimensões que fazem parte da competência profissional dos professores: conhecimento profissional, prática profissional e engajamento profissional (BRASIL, 2018b, p. 49). Cada uma dessas competências se desdobra em quatro competências específicas.

No Brasil, alguns documentos curriculares já contemplaram os conceitos de habilidades e competências a exemplo dos Parâmetros Curriculares Nacionais (PCN) (BRASIL 1997), Parâmetros Curriculares Nacionais do Ensino Médio (PCNEM) (BRASIL, 2000), bem como os sistemas de avaliações nacionais como Sistema de Avaliação da Educação Básica (SAEB/BRASIL, 2008) e Provinha Brasil (BRASIL, 2011). No entanto, o retorno ao modelo curricular por competências é visto com preocupação, por se consubstanciar em uma perspectiva reducionista do conhecimento a esquemas e modelos, em detrimento de um modo processual de compreensão curricular. (ALBINO, SILVA, 2019, p. 141).

Segundo as autoras, "o modelo de educação pautada no ensino de competências não é algo eminentemente novo" (p. 141). Elas resgatam as ideias de Sácristan $(2011$, p. 7) sobre o sentido de se trabalhar por meio de competências: a) uma sociedade de indivíduos eficientes na engrenagem do sistema produtivo, b) movimento que enfoca a educação como adestramento, c) uma oportunidade de reestruturar os sistemas educacionais por dentro, superando o ensino centrado no conteúdo (p. 140).

Ainda segundo Albino e Silva (2019, p. 142):

Nessa perspectiva, a formação humana é subalternizada a partir de uma série de condicionantes, sobretudo de ordem internacional. O currículo pautado nos fundamentos pedagógicos das competências é configurado como necessário não por uma necessidade nacional de pensar a formação humana integral, mas como resposta à uma demanda mundial. O texto parte da exterioridade para justificar a qualidade dos processos de aprendizagem; na própria descrição inicial, a potência discursiva não evidencia o pluralismo e as próprias condições da escola brasileira e nem mesmo um breve perfil de quem são os discentes para quem foi elaborada a proposição curricular. As respostas clássicas do currículo não são contempladas nessa descrição: para quem se destina esse o conjunto de habilidades e competências? Quem é esse aluno brasileiro que será mediado por saberes "comuns"?

As competências são um dos pontos principais de alinhamento entre a BNCFormação e a BNCC, pois esse modelo de formação por competências no qual se 
pautam "insiste na lógica de produção de saberes pelo caminho objetivista em que, alunos e professores são pensados como receptores de modelos educacionais pensados por 'especialistas'”' (ALBINO, SILVA, 2019, p. 150).

O texto da BNCC, por exemplo, usa como justificativa a organização por competências, baseada em exigências da Organização para a Cooperação e Desenvolvimento Econômico (OCDE) e de avaliações internacionais. Como nos apontam Albino e Silva (2019), a "OCDE é uma das grandes propositoras da educação baseada em competências com fornecimento de modelos de manuais e estratégias de avaliação" (p. 150). Nessa perspectiva, o currículo se torna um modelo que se presta a atender às perspectivas do mercado tão em alta desses materiais prontos e vendidos por grandes organizações.

A fim de compreendermos melhor a relação entre as duas Bases, partilharemos agora nossas impressões sobre a BNCC.

\section{O SEGUNDO PONTO - ONDE OS HINDUS VEEM UMA VACA SAGRADA, OUTROS VEEM UM GRANDE HAMBÚRGUER ${ }^{12}$ : A BNCC DO PONTO DE VISTA DA SUA IMPOSSIBILIDADE}

A Base Nacional Comum Curricular (BNCC) tem como primeiro marco legal/ histórico a Constituição Federal de 1988, que previu a fixação de conteúdos mínimos para assegurar a formação básica comum e o respeito aos valores culturais e artísticos, nacionais e regionais. A BNCC é apresentada como um documento de caráter normativo que define o conjunto orgânico e progressivo de aprendizagens essenciais que todos os alunos devem desenvolver ao longo das etapas e modalidades da Educação Básica, definindo-se como um documento "completo e contemporâneo, que corresponde as demandas do estudante desta época, preparando-o para o futuro" (BRASIL, 2018a, p. 5).

Nessa introdução ao documento acima citado, podemos apontar alguns equívocos nas afirmações apresentadas. Em primeiro lugar, a Constituição Federal prevê a fixação de conteúdos mínimos para assegurar uma formação comum em âmbito nacional, mas também prevê que os aspectos regionais sejam respeitados, por isso mesmo define como mínima a parte comum. No entanto, a BNCC se afirma como um "documento completo" (BRASIL, 2018a, p. 5) e assim o é, ao

${ }^{12}$ Conf. Galeano, 1999. 
normatizar em suas 600 páginas listagens extensas de conteúdos a serem trabaIhados em cada disciplina de cada ano de escolaridade.

Nesse sentido, o que deveria indicar ou resguardar o mínimo, como previsto na Constituição, passa a ser o máximo, de forma que deixa de fora conhecimentos, valores e culturas locais, desconsiderando outras formas de conhecimento, percebendo e valorizando somente o que é hegemonicamente reconhecido como conhecimento escolar. Assim, denomina-se como comum o que é hegemônico, reforçando a subalternização de sujeitos e práticas sociais portadores de outros modos de estar no mundo, de forma a gerar um empobrecimento do horizonte de possibilidades de conhecimento e, consequentemente, outras possibilidades de futuro. Ainda, a elaboração de um documento com conteúdos que devem ser obrigatoriamente aprendidos pelos estudantes reduz o direito à educação a uma obrigação de aprender apenas aquilo que é elencado no documento, reduzindo os sujeitos de conhecimentos a sujeitos de ignorâncias (OLIVEIRA; SÜSSEKIND, 2018).

Outro ponto discutível na apresentação é a ideia da educação como uma preparação para o futuro. Nessa visão, ignora-se o estudante como um sujeito que já é cidadão possuidor de saberes, culturas, experiências e valores, só valorizando o que ele será no futuro. Santos afirma que a razão hegemônica é proléptica, devido a uma compreensão de futuro como a superação linear e infinita do presente, ou seja, entende que o futuro é sempre uma evolução/progresso do que temos agora. Por ser proléptica, é irrelevante, para essa razão, voltar-se às ações do presente e pensar sobre as possíveis implicações dessas no futuro, entendendo-o como um acontecimento independente do que esteja sendo tecido no presente, já que seria o adiante sempre melhor do que o agora, mesmo que elementos históricos contradigam essa máxima, pois, apesar de todo o conhecimento científico historicamente acumulado, vivenciamos grandes guerras, a iminência de escassez dos recursos naturais e a profunda desigualdade social.

Por esse mecanismo, os currículos começam a ser concebidos como territórios de desenvolvimento e se revelam bastante mercadológicos "habitando discursos, programas e fomentos de grandes organizações financeiras". (SÜSSEKIND, 2014, p. 1515).

Oliveira (2013), ao tratar desse ideário de que a escola prepara para o futuro, elucida que devemos atuar no sentido "não de uma educação para a cidadania, mas de uma educação na cidadania, que entende o aluno como um cidadão em 
processo de educação" (OLIVEIRA, 2013, p. 199), rompendo, assim, com um modelo dominante "que pressupõe que os alunos só se tornam cidadãos depois de devidamente educados para tal".

Os fundamentos pedagógicos da BNCC, apresentados em duas páginas do documento, têm como foco o desenvolvimento de competências que, como afirma o documento, têm a mesma visão adotada nas avaliações internacionais..

Desse modo, ao adotar esse enfoque, a BNCC indica que as decisões pedagógicas devem estar orientadas para o desenvolvimento de competências. Por meio da indicação clara do que os alunos devem "saber" (considerando a constituição de conhecimentos, habilidades, atitudes e valores) e, sobretudo, do que devem "saber fazer" (considerando a mobilização desses conhecimentos, habilidades, atitudes e valores para resolver demandas complexas da vida cotidiana, do pleno exercício da cidadania e do mundo do trabalho), a explicitação das competências oferece referências para o fortalecimento de ações que assegurem as aprendizagens essenciais definidas na BNCC (BRASIL, 2018a, p. 13).

Embora o documento afirme que a BNCC seja uma demanda da sociedade que tenha sido amplamente discutida pela sociedade civil e, ainda, que seria a solução para as desigualdades educacionais existentes no país, o primeiro contato que tivemos com a ideia da BNCC foi por meio de uma propaganda veiculada na televisão pelo Ministério da Educação. No vídeo, aparecem diversas crianças de todas as regiões do Brasil indo para a escola, uma saindo de uma casa na favela, outra saindo de uma casa em uma área rural, enquanto o narrador afirma que, com a Base, todos os estudantes brasileiros, sejam de escola pública, sejam de escola particular, terão os mesmos direitos de aprendizagem. Por fim, o narrador afirma que "Isso é bom. Se a base da educação é a mesma, as oportunidades também serão".

As influências desse modelo de pensamento ainda se fazem notar no discurso e no imaginário de educadores, que compreendem existir aqueles que fazem políticas e aqueles que as implementam (ou deveriam). Essa ideia é impregnada de uma linha de pensamento mais ampla, legado do paradigma científico, de que ao sujeito comum só cabe o fazer. Nessa lógica, o fazer e o pensar estão em campos separados (REIS, 2014).

As assimetrias causadas pela separação do fazer e do pensar incutidas nas entrelinhas dos textos das Bases estabelecem os próprios caminhos para sua crítica. Sobre tal aspecto, estabelecemos um paralelo com o clima paradoxal do 
tempo presente, tempo que Santos (2006) entende como de perguntas fortes com respostas fracas. Ou seja, o problema do estabelecimento de Bases, para quaisquer aspectos da prática educativa, reside na própria incompreensão de sua origem que se fundamenta no privilégio de seus cânones em detrimento de outras noções, que seriam necessárias à produção de melhores respostas, mais fortes.

Logo, vivemos um tempo de buscas intensas por respostas apropriadas às perguntas fortes que nos são colocadas e que possam ajudar na compreensão do tempo em que vivemos (SANTOS, 2008). As particularidades desse tempo de perguntas fortes e respostas ainda fracas estão na ideia de que suas abordagens podem variar de cultura para cultura e de região para região, saindo do lugar de totalidade racional ou de pontos de vista únicos, pregado pela ciência moderna, de forma a criar uma discrepância no entendimento das perguntas fortes e das respostas necessárias aos entendimentos questionados.

\section{O TERCEIRO PONTO - DO PONTO DE VISTA DE UMA MINHOCA, UM PRATO DE ESPAGUETE É UMA ORGIA ${ }^{13}$ : UMA BREVE DISCUSSÃO SOBRE CURRÍCULO, COTIDIANOS, RAÍZES E OPÇÕES}

Defendemos, e não estamos sós, que os processos formativos e os currículos são produzidos cotidianamente nas escolas, nas relações alunos-professores, nas conversas nos corredores, na sala dos professores, nas reuniões pedagógicas e nos planejamentos que são elaborados pelos docentes. Ou seja, os currículos são praticados e pensados (OLIVEIRA, 2012) nos cotidianos.

Segundo Santos (2008), experimentamos um tempo confuso, de crise e transição, um tempo de equação entre raízes - entendidas como o pensamento de tudo aquilo que é profundo, permanente, único e singular - e opções - pensamentos de tudo aquilo que é variável, efêmero e substituível, em consonância com a superação da razão indolente. Para Boaventura, a eficácia dessa equação assenta-se numa dupla astúcia e na necessidade de se reinventar o passado, viver o presente para assim vislumbrar um futuro. Sobre isso, tomamos os dizeres de Santos (2008) quando afirma que:

Em primeiro lugar, a astúcia do equilíbrio entre o passado e o futuro. 0 pensamento das raízes apresenta-se como um pensamento do passado

${ }^{13}$ Conf. Galeano, 1999. 
contraposto ao pensamento das opções, o pensamento do futuro. Trata-se de uma astúcia porque, de facto, tanto o pensamento das raízes, como o das opções são pensamentos do futuro, orientados para o futuro. O passado é, nesta equação, tão-só uma maneira específica de construir o futuro. (SANTOS, 2008, p. 55).

Assim, nestes tempos atuais, sobretudo no cenário político brasileiro, de profunda instabilidade política, as opções estão inscritas como possibilidades/ alternativas dentro dos limites dados pelas raízes - estruturas que nos transcendem e que condicionam as opções. Podemos trabalhar a partir da ideia de que a superação do que já existe se manifesta no cenário da equação entre essas raízes e opções, que nos mostram alternativas e possibilidades, mas também limites.

Gonçalves (2018a), a partir das discussões de Boaventura de Sousa Santos, aponta que precisamos buscar o equilíbrio, a simetria entre as raízes e opções. No entanto, sabemos que, assim como no conflito entre regulação e emancipação, está longe de haver superação de um ou outro, porque "enquanto certos tipos de opções pressupõem o predomínio discursivo das raízes, outros tipos pressupõem a sua secundarização [...] o jogo é sempre das raízes para as opções e das opções para as raízes" (SANTOS, 2008, p. 55).

Faz-se necessário compreender, então, a partir da discussão que nos propusemos a realizar, que a impossibilidade da consolidação de Bases, sejam elas para a escola básica, sejam elas para o processo de formação de professores, recai sobre a dificuldade, ou ainda a impossibilidade, de captarmos, de forma plena e como uma única referência, ou único ponto de vista, os conhecimentos e suas formas de tessituras que são elaborados e compreendidos no processo histórico da sociedade (GONÇALVES, 2018a; 2018b; 2020).

Santos (2008) nos diz que esse jogo de movimento e de oposição entre raízes e opções se desenvolve com o lluminismo, quando as raízes assumiram claramente outro modo de existência: como opções. As raízes, em seu vasto campo cultural e político, impõem razões e formas prescritivas de compreensão do mundo, mas, quando estão colocadas na sociedade para consumo e uso, transformam-se por meio das opções nelas inscritas e criam a partir daí um campo imenso de possibilidades.

Ao longo das muitas pesquisas com os cotidianos escolares que desenvolvemos, percebemos que as propostas curriculares centradas nas raízes, em processos reflexivos de concretização, modificam-se, são (re)vistas por meio de movimentação e das opções inscritas nas diferentes realidades que encontram. 
Afinal, são elas que permitem aos professores darem, ou ainda proporem, novos rumos para suas práticas.

Assim, assentar o processo formativo numa Base, ou seja, na fixação de conhecimentos e currículos impostos, é, para nós, assumir a ideia de que os pontos de vista são únicos.

Portanto, é necessário problematizar o sentido de uma Base Nacional Comum que pretende retirar o movimento que se produz na equação entre raízes e opções. Professores se apropriam de diferentes métodos, técnicas e opções teórico-metodológicas distintas, ou englobam diferentes vertentes, sem romperem com as raízes, e também encontram e tecem opções criando outros currículos cotidianamente. Como aprisionar esses processos dentro de uma BNCC ou ainda trabalhar com uma perspectiva de formação que busca, a partir de uma ideia de homologia de processos, formar professores?

O espaço e o tempo são multifacetados e formados por sujeitos enredados em muitas concepções de mundo, com subjetividades distintas e que praticam suas ações de formas também distintas. Nas escolas é assim e nos cursos de formação também. Professores, desde sua formação inicial, fazem escolhas, praticampensam (OLIVEIRA, 2013), criam e modificam os currículos, sendo difícil compreender os elementos que envolvem e influenciam essas escolhas.

Oliveira (2012) aponta "que em virtude de tantos enredamentos, além - ou apesar da - imprevisibilidade, temos também limites" (n. p.). Limites advindos daquilo que Boaventura identifica como raízes, aquilo que nos vincula ao passado, mas não só a um tempo passado, enreda-nos às nossas origens, à nossa ancestralidade, aos nossos elementos constitutivos mais estruturais e profundos, com os quais é difícil romper.

Santos (2006) já nos alertou para a necessidade de compreender que, no espaçotempo da escola, as ações se apresentam inscritas em um campo de (im) possibilidades, visto que as práticas são operacionalizadas entre as raízes e as mobilidades de opções. Em outras palavras, as ações ocorrem entre aquilo que nos constitui mais profundamente e as possibilidades e alternativas que comportam para além do já sabido e feito.

Freire (2005) também nos ajuda ao apontar que a autonomia, a democracia e a liberdade, ainda que de forma utópica, são elementos fundantes a partir dos quais diferentes grupos que compõem uma sociedade negociam seus diversos interesses, tanto particulares quanto sociais. 
Autonomia pressupõe, para além da capacidade de agir por si, uma relação de interlocução e situações de aprendizagem cooperativas e solidárias, em que a democracia e a liberdade estão presentes. Nesse processo, o papel dos professores é atuar como mediadores/as do ensino-aprendizagem, para dar forma estética e ética ao ato de ensinar.

Por isso, longe de tecer práticas relacionadas a uma autonomia individual, os vários processos formativos e a tessitura do currículo em rede nos cotidianos necessitam estar vinculados a uma sensibilidade capaz de entender o outro e à disposição para a luta pela educação na qual acreditam.

Nesse aspecto, Contreras (2012) afirma que não podemos analisar a autonomia docente sob uma ótica individualista, visto que a autonomia, assim como os valores morais, é resultante de uma prática social. Portanto, não faria sentido falar que professores são autônomos/as, mas sim que operam com opções e movimentos próprios, atuando de maneira autônoma.

Um aspecto importante a ressaltar é que, no processo de constituição do que hoje são nossas raízes, a modernidade e suas nuances de racionalização influenciam a profissão docente e, com isso, o papel dos professores e suas atribuições de ensino. Em meio a essas raízes e a tantas opções que elas comportam, mas não necessariamente de validade reconhecida, percebemos que a BNC-Formação e a BNCC pretendem reduzir o papel de professores ao de aplicadores/as de programas e pacotes curriculares.

Parte-se da ideia de que o que se passa nos diferentes contextos escolares é irrelevante, criando-se um ideal de escola, planejada de fora e "do alto", que é compreendida como "lócus de aplicação desses planos". De fora, são enviadas políticas curriculares e verifica-se o trabalho realizado lá dentro por meio de provas que se dirigem à aferição da qualidade dos produtos. Comumente a culpa por resultados insatisfatórios (fracasso escolar) recai sobre professores e estudantes, pois estes falharam na aplicação dos currículos (REIS; CAMPOS, 2017, p. 5).

A partir da crença de que os contextos escolares são irrelevantes, que as diferentes realidades e conhecimentos estudantis e docentes também o são, é que foram e são produzidas essas políticas educacionais que estamos aqui a discutir.

Contreras (2012) nos ajuda a pensar nessa ideia de irrelevância quando nos diz que a "profissão docente está intimamente ligada às condições sociopolíticas, pois a educação escolar é valorizada por sua importância cultural e social" 
(GORZONI; DAVIS, 2017, p. 1391). Ou seja, não há irrelevância no processo de aprender e ensinar. O autor afirma ainda que a "autonomia no ensino é necessidade educativa e direito trabalhista" (GORZONI; DAVIS, 2017, p. 1390). Ao trabalhar a autonomia docente a partir de três aspectos que, para ele, caracterizam a profissão docente, considerando as exigências do trabalho educativo que, de certa maneira, emergem das conversas entre professores - a obrigação moral, o compromisso com a comunidade e a competência profissional -, Contreras insere um outro ponto de vista sobre ser professor e sobre a sua formação.

Assim, para além de quaisquer conhecimentos específicos e de uma formação intelectual, as imagens e práticas docentes estão intimamente relacionadas a questões sociais, culturais e econômicas, diferentemente do que percebemos nas Bases aqui discutidas.

Para Freire (2005), a autonomia é uma construção cultural, não algo natural, e depende da relação do homem com os outros e destes com o conhecimento. Assim, é possível perceber que o tema da formação docente é complexo e necessita de respostas fortes e discussões potentes, e não de produção de políticas que se arvoram a enquadrar a profissão docente, como se não houvesse uma tensão entre raízes e opções.

Há diversos desafios colocados na proposta de uma Base Nacional Comum. Segundo Garcia (2007), esses desafios são políticos, pedagógicos, técnicos, teóricos e epistemológicos. Nesse sentido, voltamos mais uma vez à discussão que abre este texto quando Alves (2014) nos alerta sobre as soluções fáceis para aquilo que deveria abarcar grandes discussões com as muitas e diversas posições, como é o caso dessa BNC da Formação. Segundo Garcia (2007), "estes [desafios] necessitam ser considerados e problematizados em suas especificidades, mas permanentemente articulados, por sua interdependência, no processo e trajetória que compõe a formação dos professores" (p. 23).

\section{UM PONTO VISTA “FINAL" - DO PONTO DE VISTA DO SUL, O VERÃO DO NORTE É INVERNO ${ }^{14}$ : O QUE FALAM OS PROFESSORES SOBRE AS POLÍTICAS DE CURRÍCULO E FORMAÇÃO?}

Ao logo deste texto, apresentamos uma discussão sobre as propostas da BNC-Formação que nos levou a discutir também a BNCC, dialogando com a ideia

\footnotetext{
${ }^{14}$ Conf. Galeano, 1999.
} 
de que os tantos pontos de vista presentes nas tensões próprias das discussões que envolvem os dois campos, currículo e formação docente, são apagados nas escrituras dos dois documentos.

Nestes tempos de buscas intensas por respostas apropriadas às perguntas fortes que nos são colocadas, temos um esvaziamento denunciado por Alves já em 2014.

Pensar nas impossibilidades de Bases Nacionais Comuns é trazer à tona as particularidades desse tempo de perguntas fortes e respostas fracas, colocando-o sob suspeita. Na perspectiva de Paulo Freire (2005), a leitura do mundo vai-se aprofundando e ampliando a partir da possibilidade de que os sujeitos, em seus processos formativos e experienciais, possam conviver com uma leitura de mundo mais ampla. Ou seja, a leitura do mundo é bem mais do que uma mera "capacitação" para melhor compreendê-lo.

A questão que se coloca é: os professores vivenciam a sua docência conforme as expectativas e demandas oriundas de seus contextos de trabalho, e isso só é possível se compreendermos que a formação está para além do que está colocado nessa Base Nacional Comum da Formação, isto é, a docência é espaço e tempo de criação e de produção de conhecimentos, bem como de possibilidades que se encontram na relação entre raízes e opções.

Indo além, podemos marcar também as ideias de autonomia trazida por Contreras (2012), uma autonomia que não se relaciona com a individualidade, sendo necessário que se compreenda que professores não podem ser "formados" a partir de uma BNC que os considera, individualmente, redentores das mazelas sociais, podendo ser culpabilizados pelas baixas notas em exames nacionais e internacionais, pois a formação docente deve estar pautada numa referência crítica, ética e que defenda um processo de autonomia docente que compreendemos com Contreras (2012) como espaço de direito trabalhista.

Nesse sentido, o Estado precisa ser responsabilizado e cumprir sua parte no acordo social, defendendo e definindo políticas públicas que sejam voltadas ao bem viver da nação. Nesse caso, a escola não pode, sozinha, compensar a origem socieconômica do aluno ou outras questões relacionadas ao desempenho escolar, como afirmado no documento (BRASIL, 2018b, p. 5).

Trazemos aqui, apenas como ilustração, trechos de uma conversa que tivemos com colegas docentes do ensino superior e da educação básica no 
grupo de pesquisa ao qual estamos ligados. O que estas docentes apontam sobre o tema?

A aprovação da BNC trouxe um conjunto de problematizações para nós, professores que atuamos na formação docente, a começar pela verticalidade do documento, que nos impõe uma concepção de prática pedagógica, de formação e de currículo. Trata-se de um texto que não conversa com a trajetória e com os saberes da/na formação docente que nós produzimos, todos os dias, junto com estudantes e professores da educação básica, estudantes e professores do ensino superior. Quando uma política pública não conversa com aquilo que é criado cotidianamente pelos atores que lidam diretamente com os efeitos dessa mesma política, torna-se possivel prever a burla, a insurgência, a desobediência. (Patricia Baroni ${ }^{15}$ ).

Acho que são políticas, como muitas outras que já surgiram, que acreditam que, para ensinar, basta seguir manuais. Visões distorcidas do ensino, de educação, de currículo... uma lástima. A BNC da formação (resolução 2/2019) e a BNCC, especificamente, são políticas educacionais que desqualificam e subestimam os professores e as professoras da Educação Básica e todos os estudantes (principalmente das escolas públicas), partindo do princípio de que basta o mínimo e de que não somos pensadores, criadores, pesquisadores, mas reprodutores de manuais, obedientes repetidores de ações previamente descritas, coitados, mal sabem que somos muito mais... A gente incomoda porque nossas aulas são inéditas, são inventadas, são artesanais, são únicas e irrepetíveis. Não há prescrição capaz de definir os currículos e conhecimentos em circulação em nossas salas de aula. Algemas e amarras ideológicas incomodam muito, mas não impedem nossas reinvenções cotidianas. (Viviane Lontra).

Todo o processo de produção da BNCC, atravessada por interesses politiqueiros e empresariais, esvaziada das escolas e daqueles a movem, a maculam no nascedouro. Só a compreensão de que um único documento possa dar conta da diversidade, variedade e multinecessidades curriculares de um país tão grande e desigual como o nosso, já demonstra que as intenções que moveram sua implementação não são as mesmas daqueles que lutam por justiça social e cognitiva. Embalado em um discurso enganoso de igualdade, dificulta a implementação da equidade, na adaptação curricular à situação concreta, observando-se os critérios de justiça. Da mesma forma,

${ }^{15}$ Patrícia Baroni, Viviane Lontra, Soymara Emilião e Simone Alencastre são docentes do ensino superior ou da Educação Básica e colegas do Grupo de Pesquisa Conversas entre Professores: Alteridades e Singularidades, que realiza pesquisas pautadas nas narrativas docentes. 
a BNCC para a formação de professores caminha no mesmo erro, seja no tratamento daqueles em situações desiguais, desconsiderando os diversos contextos docentes ou, ao apagar a importância do professor-pesquisador e da autonomia docente, dando ênfase a uma tecnicidade que esvazia a própria essência de ser-professor: a reflexão, a pesquisa e a criticidade. É um ato político cotidiano daqueles que lutam por uma escola pública, laica e de qualidade para todos não reconhecer sua legitimidade, boicotá-la e denunciá-la, em prol de currículos úmidos das vidas e de experiências dos praticantes das escolas. (Soymara Emilião).

A BNCC e a BNC da formação são documentos com propostas prescritivas e instrumentais, com predominância no "saber-fazer", que desconsideram a concepção mais ampla de formação pautada na construção coletiva e solidária de conhecimento e que coloca o professor como mero "executor" de um suposto currículo preestabelecido, que não reconhece as singularidades e complexidades dos cotidianos das escolas. A DCN da formação de professores, homologada em dezembro de 2019, está pautada fortemente na BNCC e configura-se um retrocesso nas políticas públicas de formação inicial e continuada. (Simone Alencastre).

A partir das narrativas acima, fica perceptível o lugar da criação das múltiplas opções que, muito embora surgidas das raízes, precisam tomar lugar de destaque e serem confrontadas com esse lugar construído como "competência técnica", atrelada a processos de escolarização e identificada apenas com o trabalho educacional prescrito, sobretudo quando centradas numa Base.

Pensar para além de uma Base, ou seja, tensionar que a formação de professores e de currículos não se enquadra em diretrizes únicas é um dos maiores desafios que se colocam hoje para problematizar os processos de formação que têm constituído as práticas no campo da educação, não só para podermos esboçar novas respostas, mas também, principalmente, para promover outras perguntas, outras raízes e outras opções.

Por fim, destacamos que a formação de professores precisa contemplar os aspectos das complexas redes de saberes e práticas, tecidas e compartilhadas, recusando os perversos processos de massificação impostos pelo modelo da BNC-Formação e da BNCC, devendo, sim, estar pautada na ideia de que docentes são produtores de currículos, de seus materiais pedagógicos e dos processos de avaliação, e não meros transmissores do que vêm predeterminado pelas políticas educacionais que estão sendo desenhadas para formação docente. 


\section{REFERÊNCIAS}

ALBINO, A. C. A.; SILVA, A. F. BNCC e BNC da formação de professores: repensando a formação por competências. Revista Retratos da Escola, Brasília, v. 13, n. 25, p. 137-53, jan./maio 2019. Disponível em: http://retratosdaescola.emnuvens.com.br/rde/article/ view/966. Acesso em: 28 jul. 2020.

ALVES, N. Sobre a possibilidade e a necessidade curricular de uma base nacional comum. Revista e-Curriculum, São Paulo, v. 12, n. 3, p. 1464-79, out./dez. 2014. Disponível em: https://revistas.pucsp.br/curriculum/\%20article/viewFile/21664/15948. Acesso em: 28 jul. 2020.

BRASIL. Ministério da Educação. Base Nacional Comum Curricular (BNCC). Educação é a base. Brasília-DF: MEC, 2018a.

BRASIL. Ministério da Educação. Proposta para Base Nacional Comum da Formação de Professores da Educação Básica. Brasília-DF: MEC, 2018b.

CENTRO DE ESTUDOS E PESQUISAS EM EDUCAÇÃO, CULTURA E AÇÃO COMUNITÁRIA [CENPEC]. Quem somos. São Paulo: CENPEC, [s.d.]. Disponível em: https://www.cenpec. org.br/quem-somos. Acesso em: 26 maio 2020.

CONTRERAS, J. Autonomia de Professores. São Paulo: Cortez, 2012.

FREIRE, P. Pedagogia da Autonomia: saberes necessários à prática educativa. São Paulo: Paz e Terra, 2005.

GALEANO, E. De pernas pro ar: a escola do mundo ao avesso. Rio de Janeiro: LP\&M, 1999.

GARCIA, A. Sobre os híbridos e "os outros" na/da formação de professores: a "cultura ordinária" no enredamento das práticas e das subjetividades. In: SEMINÁRIO INTERNACIONAL AS REDES DE CONHECIMENTOS E A TECNOLOGIA, 5., 2007, Rio de Janeiro. Anais [...] Rio de Janeiro, 2007.

GONÇALVES, R. M, MACHADO, T. Mara Rezende, Maria José Nascimento Correia. A BNCC na contramão das demandas sociais: planejamento com e planejamento para. Práxis Educacional, , v. 16, n. 38, p. 338-51, jan. 2020. Disponível em: http://periodicos2.uesb. br/index.php/praxis/article/view/6012. Acesso em: 26 maio 2020.

GONÇALVES, R. M. Bricolagens praticadas e políticaspráticas de currículos nos cotidianos escolares. 2018. Tese (Doutorado em Educação) - Universidade do Estado do Rio de Janeiro, Rio de Janeiro, RJ, 2018a. 
GONÇALVES, R. M. Conversas sobre práticas e currículos entre professoras: artesania e maneiras de fazer o cotidiano escolar. Linguagens, Educação e Sociedade, Teresina, Ano 23, Edição Especial, dez. 2018b. Disponível em: https://revistas.ufpi.br/index.php/ lingedusoc/article/view/7876. Acesso em: 26 maio 2020.

GORZONI, S. P.; DAVIS, C. O conceito de profissionalidade docente nos estudos mais recentes. Cadernos de Pesquisa, v. 47, n. 166, p. 1396-1413, out./dez. 2017. Disponível em: https://www.scielo.br/scielo.php?script=sci_abstract\&pid=S010015742017000401396\&Ing=pt\&nrm=iso\&tIng=pt. Acesso em: 30 jul. 2020.

OLIVEIRA, I. B. de.; SÜSSEKIND, M. L. Dimensões político-epistemológicas do equívoco conservador na educação: a base curricular brasileira no contexto dos currículos nacionais. Revista Portuguesa de Educação, 2018. Disponível em: https://revistas.rcaap.pt/rpe/ article/ view/14806/12563. Acesso em: 30 jul. 2020.

OLIVEIRA, I. B. Utopias praticadas: justiça cognitiva e Cidadania horizontal na escola pública. Instrumento - Revista de Estudo e Pesquisa em Educação, Juiz de Fora, v. 15, n. 2, p. 191-201, jul./dez. 2013. Disponível em: https://periodicos.ufjf.br/index.php/ revistainstrumento/article/view/18872. Acesso em: 30 jul. 2020.

OLIVEIRA, I. B. Currículo como criação cotidiana. Petrópolis: DP et Alli, 2012.

REIS, G. R. F. S. Por uma outra Epistemologia de Formação: conversas sobre um projeto de formação de professoras no município de Queimados. 2014. 196 f. Tese (Doutorado em Educação) - Faculdade de Educação, Universidade do Estado do Rio de Janeiro, Rio de Janeiro, RJ, 2014.

REIS, G. R. F. S; CAMPOS, M. S. N. Ser professor: embates da profissão docente. REUNIÃO NACIONAL DA ANPED, 38., 1 a 5 de outubro de 2017, São Luís, MA. Anais [...]. São Luís: ANPED, 2017. Disponível em: http://anais.anped.org.br/sites/default/files/arquivos/ trabalho_38anped_2017_GT13_188.pdf. Acesso em: 27 jul. 2020.

RODRIGUES, L. Z.; PEREIRA, B.; MOHR, A. O Documento "Proposta para Base Nacional Comum da Formação de Professores da Educação Básica" (BNCFP): dez razões para temer e contestar a BNCFP. Revista Brasileira de Pesquisa em Educação em Ciências, Belo Horizonte, v. 20, p. 1-39, jan./dez. 2020. Disponível em: https://periodicos.ufmg.br/index. php/rbpec/article/view/16205. Acesso em: 28 jul. 2020.

SANTOS, B. S. A Gramática do Tempo: para uma nova cultura política. São Paulo: Cortez, 2008.

SANTOS, B. S. Pela Mão de Alice: o social e o político na pós-modernidade. São Paulo: Cortez, 2006. 
SANTOS, B. S. Para uma sociologia das ausências e uma sociologia das emergências. Revista Crítica de Ciências Sociais, 63, p. 237-80, out. 2002. Disponível em: https://journals. openedition.org/rccs/1285. 28 jul. 2020.

SANTOS, E. O.; JOSÉ, B. N. Concepções e práticas de formação continuada na educação básica. Revista Interritórios, Caruaru, v. 2, n. 3, p. 101-20, 2016.

SÜSSEKIND, M. L. As (im)possibilidades de uma Base Comum Nacional. Revista e-Curriculum, São Paulo, v. 12, n. 3, p. 1512-29, out./dez. 2014. Disponível em: https:// revistas.pucsp.br/index.php/curriculum/article/viewFile/21667/15917. Acesso em: 27 jul. 2020.

\section{Sobre os autores:}

Graça Regina Franco da Silva Reis: Doutora em Educação. Professora do Colégio de Aplicação e do Programa em Pós-Graduação da Universidade Federal do Rio de Janeiro (UFRJ). Líder do Grupo de Pesquisa Conversas entre Professores: Alteridades e Singularidades (ConPAS) - Apoio CNPq e Faperj. E-mail: francodasilvareis@gmail.com, Orcid: https://orcid.org/0000-0002-2420-0985.

Rafael Marques Gonçalves: Doutor em Educação. Professor adjunto no Centro de Educação, Letras e Artes e docente permanente do Programa de Pós-Graduação em Educação da Universidade Federal do Acre (Ufac). Líder do Grupo de Estudos e Pesquisas em Políticas, Práticas e Currículos (GpPPC). E-mail: rafamg02@gmail.com_Orcid: http://orcid.org/0000-0002-9038-1542

Recebido em: 4 de agosto de 2020 Última revisão: 18 de agosto de 2020 Aceito em: 10 de setembro de 2020 